\title{
Optimizing copper spheres for precision calibration of hydroacoustic equipment
}

\author{
Kenneth G. Foote \\ Institute of Marine Research, 5011 Bergen, Norway \\ (Received 9 September 1981; accepted for publication 20 November 1981)
}

An operational definition of backscattering cross section is developed for the wideband reception of finite echoes. This is supported by relative measurements on a set of copper spheres by each of four echo sounders operating at frequencies from 38 to $120 \mathrm{kHz}$. Experiential and theoretical arguments are advanced for the superiority of commercial, electrical-grade copper in the application. An optimization problem for determining the sphere size is then formulated, and solved for the case of calibration of a $38 \mathrm{kHz}$ echo sounder by a sphere of the described material. The solution: that the copper sphere diameter be $60.00 \mathrm{~mm}$, is tested through a variety of measurements. These demonstrate an accuracy of $0.1 \mathrm{~dB}$. The further exercise of theory indicates the feasibility of precision calibration of diverse hydroacoustic equipment by copper spheres over most of the kilohertz frequency range.

PACS numbers: 43.85.Vb, 43.30.Sf, 43.30.Dr, 43.20.Fn

\section{INTRODUCTION}

Advantages of passive, spherically symmetric targets for calibrating hydroacoustic equipment are wellknown. ${ }^{1}$ Examples include ping-pong balls, ${ }^{2,3}$ glass $^{4,5}$ and plastic ${ }^{5}$ spheres, and both hollow ${ }^{1}$ and solid ${ }^{3,6}$ metal spheres. These have been problematical for reasons of fragility, difficulty of suspension or fabrication, unknown effect of fabrication on acoustic properties, or sensitivity of these to measurement conditions. Recently, tungsten carbide spheres were proposed as reference targets for scattering measurements in the laboratory. ${ }^{6}$ It may be presumed from the detailed knowledge of the differential frequency response function displayed in Ref. 6 that both hydrophones and transducers may be calibrated by such spheres, if sufficiently short pulses are used.

What has generally not been appreciated is that elastic spheres can also be used for the precision calibration of more complicated hydroacoustic equipment, such as sonars, echo sounders, and echo integrators, outside of the laboratory and without having to operate at very short pulse lengths.

It is the present aim to justify the broader application of elastic spheres in calibration work. Theory is necessarily extended to the general case of wideband reception of finite echoes. This is supported by a series of relative measurements, which additionally witness to the excellence of copper for precision calibration spheres. An optimization problem for determining the diameter is then formulated, and solved for a sphere of commercial, electrical-grade copper to be used in calibrating a $38 \mathrm{kHz}$ echo sounder. The correctness of the solution is demonstrated by a number of independent, absolute measurements of the effective backscattering cross section.

\section{THEORY}

As an observable process, acoustic backscattering by a discrete body consists in ensonification, echo formation, and echo reception. Previous theoretical studies have ignored the manner of reception through assumption of continuous-wave ensonification ${ }^{7}$ or of hydrophone-type reception, i.e., with flat frequency response function, whether with $^{6,8}$ or without ${ }^{9}$ extraction of a monochromatic component. The effect of observing finite echoes by intrinsically wideband, frequency-sensitive devices such as sonars and echo sounders may be incorporated directly in theory. According to the filtering analogy of Fig. 1 and the usual assumption of linearity, the component processes are strictly multiplicative in the frequency domain. Given the Fourier relationship between signals and their spectra, ${ }^{10}$ expressed, respectively, in time $t$ and frequency $\omega$ domains, the spectrum $S^{\prime \prime}(\omega)$ of received signal $s^{\prime \prime}(t)$ is related to the spectra $S^{\prime}(\omega)$ and $S(\omega)$ of respective signals $s^{\prime}(t)$ and $s(t)$ by the relation

$$
S^{\prime \prime}(\omega)=S^{\prime}(\omega) H(\omega)=S(\omega) F(\omega) H(\omega),
$$

where $H(\omega)$ is the frequency response function of the receiver and $F(\omega)$ is the monochromatic scattering amplitude of the target.

The backscattering cross section $\sigma$ is usually defined theoretically with respect to the monochromatic amplitude $f$ or proportional quantity,,$^{11,12}$ with the result

$$
\sigma=4 \pi|f|^{2} \text {. }
$$

This is untenable in the case of wideband reception of finite echoes. For this, the basic definition of $\sigma$ in terms of the backscattered pressure $p_{\text {bsc }}$ and incident pressure $p_{1 \text { ac }}$ must be revised, cf. Ref. 13,

$$
\left.\left.\sigma \equiv 4 \pi r^{2}\right|_{p_{\text {bac }}}\right|^{2} /\left|p_{\text {inc }}\right|^{2},
$$

where $r$ is the effective observation range. According to this conventional definition, $\sigma$ is determined by intensities, which have meaning only for monochromatic or continuous waves. In the case of finite signals and

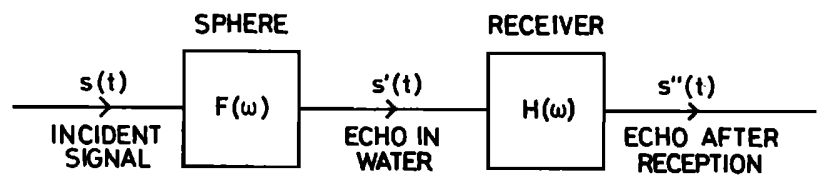

FIG. 1. Schematic diagram of acoustic backscattering as a filtering process. 
intrinisically wideband receivers, the definition can be generalized by replacing each intensity by a time integral or energy. In order to maintain the original definition in the limit of a continuous wave, the energy associated with the incident wave is calculated as though it were received, hence processed in the same manner as the echo signal. Thus, making use of Rayleigh's theorem, ${ }^{14}$

and

$$
\left|r p_{\mathrm{bac}}\right|^{2} \rightarrow \int_{0}^{\infty}|S F H|^{2} d \omega
$$

$$
\left|p_{1 \mathrm{nc}}\right|^{2} \rightarrow \int_{0}^{\infty}|S H|^{2} d \omega
$$

The new operational definition of backscattering cross section is, therefore,

$$
\sigma \equiv 4 \pi \int_{0}^{\infty}|S F H|^{2} d \omega / \int_{0}^{\infty}|S H|^{2} d \omega .
$$

Equations (2) and (3) are derived from this in the noted limit.

The calculability of Eq. (4) may be seen by an example, which may also suggest its use in choosing a calibration sphere: For solid, homogeneous elastic spheres, $F$ is given essentially by Faran, ${ }^{15}$ with recognition of the misplaced Poisson's factor by Hickling, ${ }^{9}$ and correct statement in Ref. 16. For ensonification by a pulsed sinusoidal signal of duration $T$ and center frequency $\omega_{0}, S$ has the characteristic $\sin (x) / x$ form, ${ }^{10}$ where $x=\left(\omega-\omega_{0}\right) T / 2$. $H$ is a characteristic of the receiver. It is illustrated in Fig. 2 for Sim rad echo sounders with nominal operating frequencies of 38 , $49.5,70$, and $120 \mathrm{kHz}$.

\section{CONFIRMATION}

In order to confirm the extended theory and investigate various candidate materials, a first experiment was performed with integral elastic spheres machined from aluminum, brass, copper, several steels, zinc, and a plastic. Measurements were made with the echo sounders whose frequency response functions are described in Fig. 2. Center frequencies and pulse durations are given in Table I. Hydrographic observations at the depth of sphere suspension under measurement allowed specification of the sound speed ${ }^{17}$ and density, ${ }^{18}$ which were found to be $1493 \mathrm{~m} / \mathrm{s}$ and $1022 \mathrm{~kg} / \mathrm{m}^{3}$.

Comparison with theoretical calculations based on tabulated values of the elastic constants ${ }^{19}$ gave good agreement at all frequencies only in the case of the copper spheres. Slightly better agreement was obtained by adjustment of the two sound speeds in copper: The longitudinal sound speed was measured by a pulsed resonance method similar to that of Ref. 20, but adapted by $\mathrm{H}$. Hobæk of the Department of Physics of the University of Bergen. The result of the measurement was $4760 \pm 10 \mathrm{~m} / \mathrm{s}$, which is consistent with the values given by application of the best available
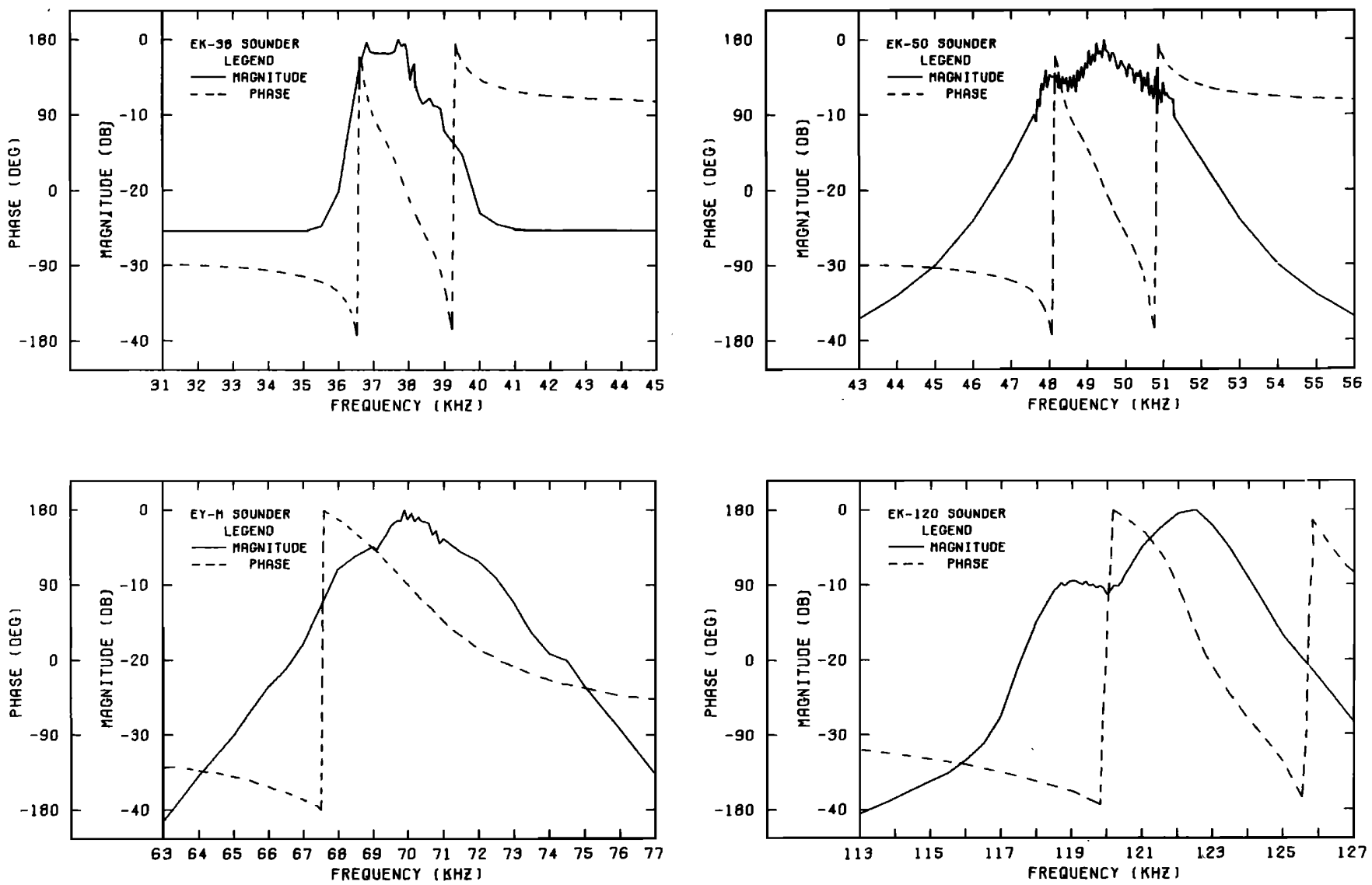

FIG. 2. Frequency response functions of four Simrad echo sounders. Each component function was measured with the exception of the phase part of the EK-50 function, which was simulated by simple translation in frequency of the phase part of the EK-38 function. 
TABLE I. Center frequencies and durations of pulses transmitted by four Simrad echo sounders.

\begin{tabular}{|c|c|c|c|c|}
\hline \multirow{2}{*}{$\begin{array}{l}\text { Echo } \\
\text { sounder }\end{array}$} & \multicolumn{2}{|c|}{ Center frequency $(\mathrm{kHz})$} & \multicolumn{2}{|c|}{ Pulse duration (ms) } \\
\hline & Nominal & Measured & Nominal & Measured \\
\hline EK-38 & 38.0 & 38.0 & 0.6 & 0.75 \\
\hline $\mathrm{EK}-50$ & 49.5 & 49.6 & 0.6 & 0.58 \\
\hline EY-M & 70.0 & 68.4 & 0.6 & 0.62 \\
\hline EK-120 & 120.0 & 120.4 & 0.6 & 0.69 \\
\hline
\end{tabular}

single-crystal data ${ }^{21}$ to the Voigt-Reuss-Hill approximation. ${ }^{22}$ The transverse sound speed was adjusted analogously with the method of Refs. 7 and 8 by means of the resonance null of the $45-\mathrm{mm}$ copper sphere near $120 \mathrm{kHz}$. This gave the value $2260 \pm 5 \mathrm{~m} / \mathrm{s}$, which is also consistent with the values prescribed by the noted application of polycrystalline theory.

Recalculation of the effective backscattering cross section in accordance with the adjusted sound speeds and the measured equipment parameters described in Table I and Fig. 2 gave the agreement with experiment shown in Fig. 3. The measurements were made relatively to avoid possible biasing by having to assume an absolute calibration. The calculations were thus normalized to the $35-\mathrm{mm}$ copper sphere, whose datum for each of the four echo sounders is consequently not significant.

\section{SPHERE OPTIMIZATION}

\section{A. Material}

The uniform success with copper and consideration of its outstanding physical properties, corrosion resistance to seawater, ${ }^{23}$ global availability in a high state of purity, ${ }^{24}$ cheapness, and machining qualities, led to its choice as the best material for further investigation. The fact of its being elemental or nearly elemental in its primary, commercial, electrical-grade forms; namely, oxygen-free copper and electrolytic tough-pitch copper, ${ }^{25}$ is especially advantageous for the elasticity. This may be expected to vary only slightly with trace element content. In contrast, the elasticity of other metals, e.g., steels and nonferrous alloys, may be expected to vary significantly with the precise alloying proportions, for the very existence of alloys is often predicated by the need for special mechanical properties. Attainment of these naturally affects or determines the elasticity. Examples of the systematic influence of alloying on elastic properties are provided by Refs. 26-29, which include both single-crystal and polycrystalline copper.

Another advantage with the choice of copper is its cubic structure. ${ }^{21}$ The elastic properties may thus be unaffected by texturing. ${ }^{30}$ Careful examination of the pertinent references of Ledbetter and Naimon ${ }^{30}$; namely, the present Refs. 27 and 31-34, suggests that this is the case for the acoustically critical rigidity modulus
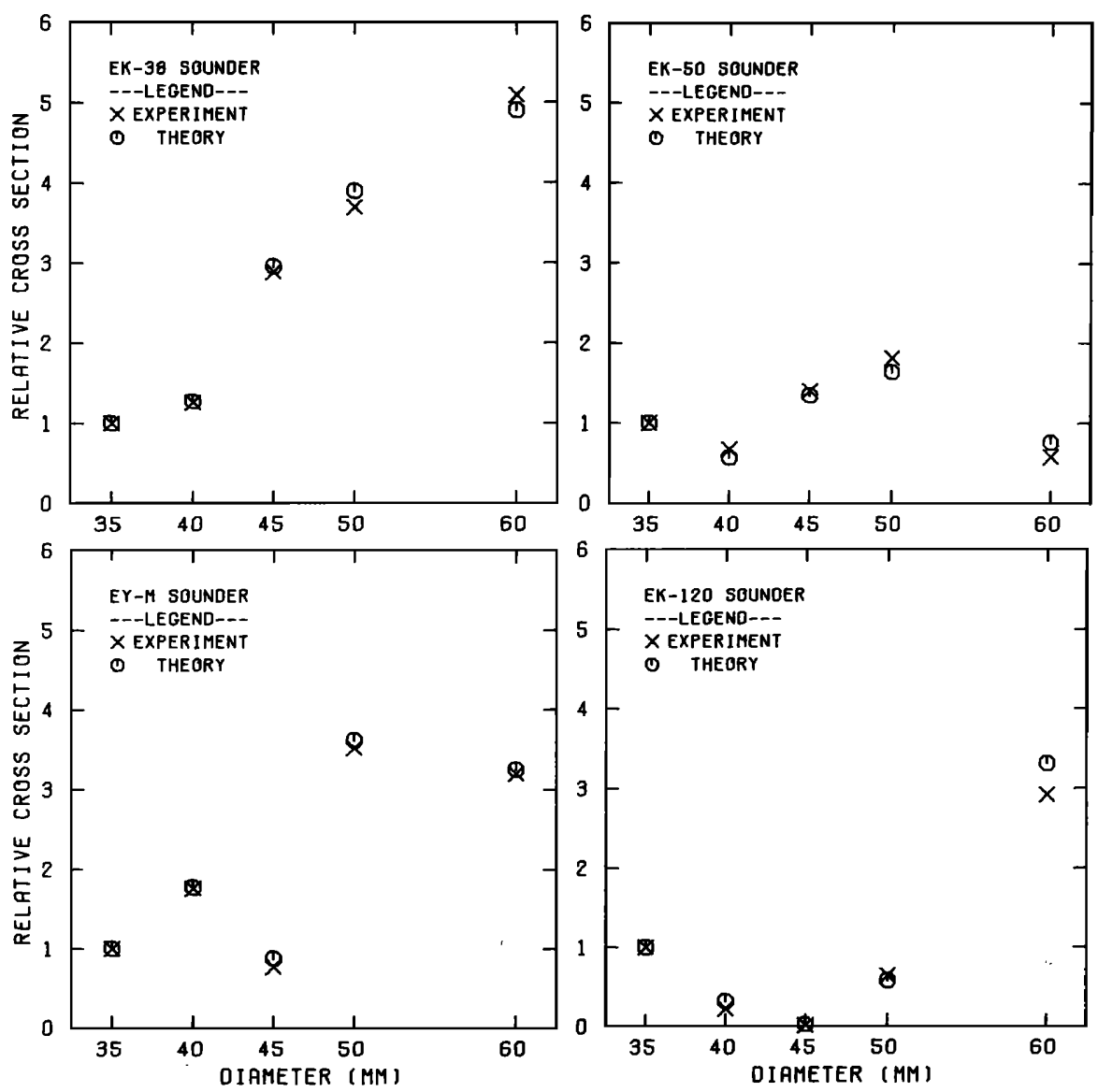

FIG. 3. Comparison of experimental and theoretical backscattering cross sections of five copper spheres, normalized to the $35-\mathrm{mm}$ sphere, as observed with or calculated for the respective receiver frequency response functions shown in Fig. 2. 


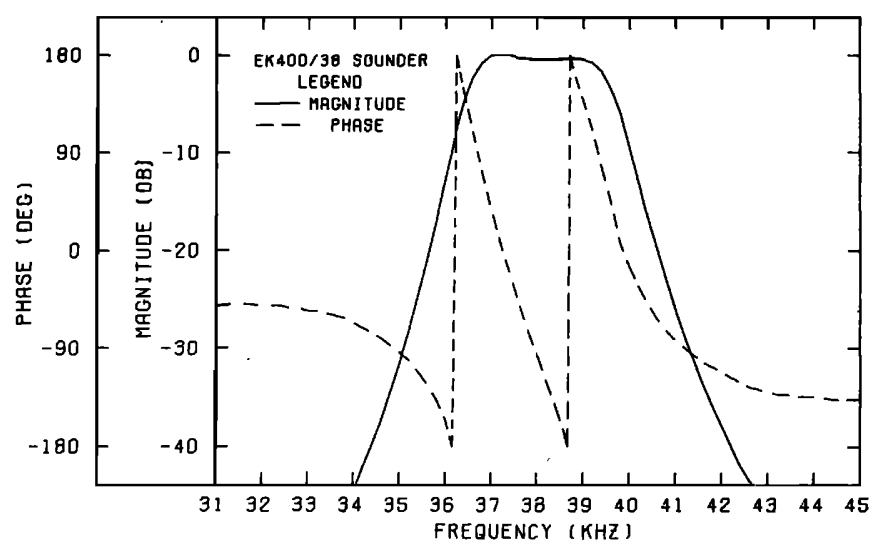

FIG. 4. Measured frequency response function of the Simrad EK-400/38 echo sounder.

of commercial, electrolytic copper. The commercial, electrical-grade copper of the current application also seems to share this property, for its measured rigidity modulus, $46.86 \pm 0.06 \mathrm{GPa},{ }^{35}$ is consistent with the values in the five references.

\section{B. Diameter}

In order to find the best size of copper sphere for calibrating a given echo sounder or sonar over the range of conditions of likely encounter, the following optimization problem was posed: Specify the sphere diameter such that

$$
\left.\frac{d \sigma}{d \tau}\right|_{\tau_{0}}=0
$$

where $\tau$ is the temperature variable, $\tau_{0}$ is the reference temperature which lies in the range $\left(\tau_{1}, \tau_{2}\right)$, and $\sigma|\epsilon|\left(\sigma_{1}, \sigma_{2}\right)$ or other criterion. The elasticity of the copper was defined through the longitudinal and transverse wave sound speeds: 4760 and $2288.5 \mathrm{~m} / \mathrm{s}$, respectively, with implied Poisson's ratio of $0.3497 .{ }^{36}$ The density of the copper was assumed to be 8947 $\mathrm{kg} / \mathrm{m}^{3}$.

Equation (5) was solved for the Simrad EK-400/38 echo sounder under nominal operating conditions, given the requirement that the backscattering cross section be of the order of $40 \mathrm{~cm}^{2}$ and that it remain relatively constant over the temperature range $[0,30]^{\circ} \mathrm{C}$ in seawater of salinity $35 \mathrm{ppt}$. The center frequency is $38.00 \mathrm{kHz}$, pulse duration $1.00 \mathrm{~ms}$, and receiver frequency response function as shown in Fig. 4. The solution is that the sphere diameter should be $60.00 \mathrm{~mm}$, with $0.1 \%$ tolerance. For this, the backscattering cross section should lie in the range $[53.6,56.2] \mathrm{cm}^{2}$, or, according to the conventional logarithmic expression of $\sigma,{ }^{37}$ the target strength should be -33.6 $\pm 0.1 \mathrm{~dB}$.

\section{EMPIRICAL CHECKS}

The design of the optimal calibration sphere was subsequently tested by several independent, absolute measurements of the backscattering cross sections of specimen copper spheres of the described size. These are distinguished here by the method of measurement.

\section{A. Hydrophone-calibrated echo sounder}

The backscattering cross section was measured with a hydrophone-calibrated $\mathrm{EK}-400 / 38$ echo sounder and associated full-size transducer resonant at $38 \mathrm{kHz}$. This was suspended beneath the hull of a 125-ton side trawler anchored in a deep, sheltered fjord near Bergen. Each of four specimen spheres was examined. These had been obtained from three machine shops, working independently with electrolytic copper rod procured from different suppliers at different times. Of the double set of spheres ordered from the same machine shop, one was annealed after polishing. In the event, the measurements proved to be identical, and only a single datum is presented in Table II.

Additional measurements were made to determine the effect of the means of attachment of flexible suspension line to the sphere. The following three means were investigated: net bags woven of monofilament nylon in the largest possible mesh size consistent with holding the sphere securely, and loops of the same line affixed either to a copper eyebolt or epoxy weld made in a shallow bore. Again, no acoustic difference was observed.

TABLE II. Comparison of measured and predicted target strengths of the $60.00-\mathrm{mm}$ copper sphere, calculated to be optimal for the $\mathrm{EK}-400 / 38$ echo sounder.

\begin{tabular}{|c|c|c|c|c|c|c|}
\hline \multirow[b]{2}{*}{ Method } & \multicolumn{3}{|c|}{ Transmitter } & \multirow[b]{2}{*}{ Receiver } & \multirow[b]{2}{*}{ Experiment } & \multirow[b]{2}{*}{ Theory } \\
\hline & $\begin{array}{l}\text { Acoustic } \\
\text { source }\end{array}$ & $\begin{array}{c}\text { Center } \\
\text { frequency } \\
(\mathrm{kHz})\end{array}$ & $\begin{array}{l}\text { Pulse } \\
\text { duration } \\
\text { (ms) }\end{array}$ & & & \\
\hline Absolute & $\begin{array}{c}\mathrm{EK}-400 / 38 \\
\text { sounder }\end{array}$ & 38.00 & 1.00 & $\begin{array}{c}\mathrm{EK}-400 / 38 \\
\text { sounder }\end{array}$ & $-33.7 \pm 0.5$ & -33.7 \\
\hline Direct & $\begin{array}{c}38 \mathrm{kHz} \\
\text { transducer }\end{array}$ & 38.0 & 0.2 & Hydrophone & $-33.9 \pm 0.5$ & -34.2 \\
\hline Direct & $\begin{array}{l}\text { Parametric } \\
\text { acoustic array }\end{array}$ & 38.00 & 0.12 & Hydrophone & $-34.1 \pm 0.1$ & -34.2 \\
\hline Direct & $\begin{array}{c}\mathrm{EK}-400 / 38 \\
\text { sounder }\end{array}$ & 38.00 & 0.50 & Hydrophone & $-33.5 \pm 0.1$ & -33.6 \\
\hline
\end{tabular}




\section{B. Direct measurements}

Three independent measurements were made by the direct hydrophone method. This consists in interposition of a hydrophone between transducer and sphere, and measurement of the incident signal and echo. Knowledge of the acoustic field, including general perturbing effect of intermediate hydrophone, and of the hydrophone directivity allows straightforward determination of the backscattering cross section from the several measured signals.

Two of the measurements were made in a small tank of the Hydroacoustics Laboratory at the University of Bergen. For each of these the presence of substantial reverberation made separation of signal and noise essential to the success of the method.

In the first measurement, which was performed with a $10 \times 10 \mathrm{~cm}$ nickel transducer resonant at $38 \mathrm{kHz}$, the noise was removed by subtracting the rms noise amplitude from an rms signal-plus-noise amplitude. This second amplitude was estimated through a series of observations in which the sphere was moved over a distance of the order of a wavelength, about $4 \mathrm{~cm}$, along the transducer-hydrophone axis.

The second measurement was performed by means of a $38-\mathrm{kHz}$ signal generated by the parametric interaction of simultaneous pulsed sinusoids at 900 and 938 $\mathrm{kHz}$. Both the signal-plus-noise and noise waveforms were sufficiently' clean and stable to permit direct, in-phase subtraction. The measurement and signal processing was performed for each of three available spheres by G. Lien and P. Meldahl of the Department of Physics of the University of Bergen.

The third measurement was performed by means of a rig built for the purpose and suspended over the side of a vessel in Oslofjord. The equipment was standard, noise level negligible, and measurements uncomplicated, hence following the classic procedure. R. Brede of Sim rad performed the measurement on a single sphere.

Results of the several measurements described here, after necessary computation or identification of the respective energies of incident and echo waveforms, are presented in Table II.

\section{Indirect measurements}

A large number of relative measurements have been performed both during the described experiments and during recent calibration cruises. In these, the reference may be considered to be a sphere of unknown backscattering cross section. The results have been entirely consistent with theory and justify stating an accuracy for target strength differences approaching $0.01 \mathrm{~dB}$.

\section{RESULTS AND DISCUSSION}

Absolute measurements of backscattering cross section of the optimal copper sphere are stated in Table II. These are compared with theoretical calculations based on the manner and conditions of measurement. The widely varying hydrography, differing pulse durations, and different degrees of receiver processing explain the differences. The fact of the agreement of theory with experiment underscores the consistency of the operational definition of backscattering cross section presented at the outset. It also justifies the use of elastic spheres as wideband calibration targets. The evident accuracy of $0.1 \mathrm{~dB}$ further warrants the appellation of "precision" to such calibration.

A particular, serendipitous result of the mentioned indirect measurements was discovery of a method for the precision determination of the rigidity modulus of elastic materials. ${ }^{35}$ An application of this to an electrical-grade copper different from that used in the first experiment allowed determination of the transverse sound speed to within $0.06 \%$. Use of this technique should ultimately allow the target strength of elastic spheres to be specified to within $0.01 \mathrm{~dB}$, effecting a more certain calibration than that reported here.

Copper appears to be the ideal material for calibration spheres for many reasons, but its use in the envisaged $0.01-\mathrm{dB}$ calibrations cannot be described without additional specification of the elasticity until several problems are solved. The origin of these undoubtedly lies in fundamental differences in the two forms of electrical-grade copper. ${ }^{38}$ These have been investigated only incompletely, however, with respect to the elasticity. The following two questions are posed, therefore: (1) How does the elasticity of copper vary with oxygen content for the high-conductivity oxygenfree and oxygen-bearing tough-pitch coppers? (2) What is the effect of hot and cold working on the elasticity of copper when being rolled into bars of circular cross section, or what is the effect of texture on the elasticity of high-conductivity coppers?

Lest the present work be considered of theoretical interest only, it is noted that copper spheres are presently being used to calibrate echo sounders and echo integrators used on board fisheries research vessels. ${ }^{39}$ Although these devices operate at ultrasonic frequencies from about 30 to $150 \mathrm{kHz}$, theory indicates the value of optimal copper spheres for the precision calibration of all sorts of hydroacoustic equipment throughout most of the kilohertz frequency range.

\section{ACKNOWLEDGMENTS}

Technical assistance from the acoustics group at the University of Bergen, the instrumentation group at the Institute of Marine Research, and Simrad Company is gratefully acknowledged. G. Vestnes of the Institute of Marine Research is thanked particularly for his constant interest in and support of the study.

${ }^{1}$ R. H. Wallace, H. V. Hillery, G. R. Barnard, B, M. Marks, and C. M. McKinney, "Experimental investigation of several passive sonar targets," J. Acoust. Soc. Am. 57, 862-869 (1975).

${ }^{2}$ V. G. Welsby and J. E. Hudson, "Standard small targets for calibrating underwater sonars," J. Sound Vib. 20, 399-406 (1972). 
${ }^{3}$ J. J. Traynor and J. E. Ehrenberg, "Evaluation of the dual beam acoustic fish target strength measurement method," J. Fish. Res. Board Can. 36, 1065-1071 (1979).

4T. Hashimoto and Y. Maniwa, "Study of reflection loss of ultrasonic millimetre wave on fish body," Tech. Rep. Fish. Boat Lab. 8, 113-118 (1956).

${ }^{5} \mathrm{~K}$. Shibata, "Study on details of ultrasonic reflection from individual fish," Bull. Fac. Fish., Nagasaki Univ. 29, 1-82 (1970).

${ }^{6}$ L. R. Dragonette, S. K. Numrich, and L. J. Frank, "Calibration technique for acoustic scattering measurements," J. Acoust. Soc. Am. 69, 1186-1189 (1981).

${ }^{7}$ W. G. Neubauer, R. H. Vogt, and L. R. Dragonette, "Acoustic reflection from elastic spheres. I. Steady-state signals," J. Acoust. Soc. Am. 55, 1123-1129 (1974).

${ }^{8}$ L. R. Dragonette, R. H. Vogt, L. Flax, and W. G. Neubauer, "Acoustic reflection from elastic spheres and rigid spheres and spheroids. II. Transient analysis," J. Acoust. Soc. Am. 55, 1130-1137 (1974).

${ }^{9} \mathrm{R}$. Hickling, "Analysis of echoes from a solid elastic sphere in water,"J. Acoust. Soc. Am. 34, 1582-1592 (1962).

${ }^{10} \mathrm{P}$. M. Woodward, Probability and information Theory, with Applications to Radar, 2nd ed. (Pergamon, Oxford, 1964).

${ }^{11}$ P. M. Morse and H. Feshbach, Methods of Theoretical Physics (McGraw-Hill, New York, 1953).

${ }^{12}$ Electromagnetic and Acoustic Scattering by Simple Shapes, edited by J. J. Bowman, T. B. A. Senior, and P. L. E. Uslenghi (North-Holland, Amsterdam, 1969).

${ }^{13}$ L. L. Beranek, in American Institute of Physics Handbook, 3rd ed. (McGraw-Hill, New York, 1972), pp. 3-12.

${ }^{14} \mathrm{~J}$. W. Strutt, "On the character of the complete radiation at a given temperature," Philos. Mag., Ser. 5, 27, 460-469 (1889).

${ }^{15}$ J. J. Faran, Jr., "Sound scattering by solid cylinders and spheres," J. Acoust. Soc. Am. 23, 405-418 (1951).

${ }^{16}$ R. R. Goodman and R. Stern, "Reflection and transmission of sound by elastic spherical shells," J. Acoust. Soc. Am. 34, 338-344 (1962).

${ }^{17} \mathrm{~V}$. A. Del Grosso, "New equation for the speed of sound in natural waters (with comparison to other equations)," J. Acoust. Soc. Am. 56, 1084-1091 (1974).

${ }^{18} \mathrm{G}$. Dietrich, in Landolt-Bymstein Zahl enwerte und Funktionen, Vol. 3 (Springer-Verlag, Berlin, 1952), 6th ed., pp. 426-441.

${ }^{19}$ W. P. Mason, in American Institute of Physics Handbook (McGraw-Hill, New York, 1972), 3rd ed., pp. 3-104.

${ }^{20}$ W. Bez-Bardili, " Über ein Ultraschall - Totalreflektometer zur Messung von Schallgeschwindigkeiten sowie der elastischen Konstanten fester Körper," Z. Phys, 96, 761-786 (1935).

${ }^{21}$ R. F. S. Hearmon, "The elastic constants of crystals and other anisotropic materials," in Landolt-Bömstein, New Series, Group III, Vol. 11 (Springer-Verlag, Berlin, 1979), pp. 1-244.

${ }^{22} \mathrm{O}$. L. Anderson, "Determination and some u'ses of isotropic elastic constants of polycrystalline aggregates using single- crystal data," in Physical Acoustics-Principles and Methods, Vol. III, edited by W. P. Mason (Academic, New York, 1965), part B, pp. 43-95.

${ }^{23}$ P. T. Gilbert, "Chemical properties and corrosion resistance of copper and copper alloys," in Copper: The Science and Technology of the Metal, Its Alloys and Compounds, edited by A. Butts (Reinhold, New York, 1954), Chap. 18, pp. 379409.

${ }^{24} \mathrm{~L}$. Addicks, "The background of the copper industry," in Copper: The Science and Technology of the Metal, Its Alloys and Compormds, edited by A. Butts (Reinhold, New York, 1954), Chap. 18, pp. 379-409.

${ }^{25}$ R. A. Wilkins and E. S. Bunn, Copper and Copper Base Alloys (McGraw-Hill, New York, 1943).

${ }^{26} \mathrm{M}$. J. Druyvesteyn and J. L. Meyering, "Elastical constants in the system $\mathrm{Cu}-\mathrm{Zn}$," Physica (Utrecht) 8, 1059-1074 (1941).

${ }^{27}$ G. Faninger, " Die elastischen Konstanten von Kupfer-NickelVielkristallen," Z. Metallkd. 60, 601-605 (1969).

${ }^{28}$ L. M. T. Hopkin, H. Pursey, and M. F. Markham, "Precise measurements of the elastic constants of copper and silver base alloys," $Z$. Metallkd. 61, 535-540 (1970).

${ }^{29}$ L. S. Cain and J. F. Thomas, Jr., "Elastic constants of $\alpha$-phase Cu-Al alloys," Phys. Rev. B 4, 4245-4255 (1971).

${ }^{30}$ H. M. Ledbetter and E. R. Naimon, "Elastic properties of metals and alloys. II. Copper," J. Phys. Chem. Ref. Data 3, 897-935 (1974).

${ }^{31} \mathrm{~T}$. Kawai, "On the change of the modulus of rigidity in different metals caused by cold-working," Sci. Rep. Tohoku Univ. 20, 681-709 (1931).

${ }^{32} \mathrm{~F}$. Birch, "The effect of pressure on the modulus of rigidity of several metals and glasses," J. Appl. Phys. 8, 129-133 (1937).

${ }^{33}$ J. Lobdell, G. F. Shinopulos, and D. N. Fillia, "An instrument to measure transverse strain," AVCO Corp. Res. Rep. RAD-TM-63-13 (1963) (NTIS Rep. No. AD 438571).

${ }^{34}$ H. H. Wawra, " Uber die Abhängigkeit des Elastizitäts-und Torsionsmoduls gezogener Kupfer-und $\alpha$-Messingstangen von der Anlasstemperatur," Z. Metallkd. 59, 268-272 (1968).

${ }^{35}$ K. G. Foote, "Refined determination of the rigidity modulus by echo sounder measurement," in 1981 Ultra son. Symp. Proc., Chicago, IL, 14-16 October 1981 (IEEE, New York, 1981), pp. 900-903.

${ }^{36} \mathrm{H}$. Kolsky, Stress Waves in Solids (Dover, New York, 1963).

${ }^{37} \mathrm{R}$. J. Urick, Principles of Underwater Sound, 2nd ed. (McGraw-Hill, New York, 1975).

${ }^{38}$ W. R. Opie, R. W. Taubenblat, and Y. T. Hsu, "A fundamental comparison of the mechanical behaviour of oxygenfree and tough-pitch coppers," in Copper and Its Alloys, Proc. Int. Conf., Inst. Met., Amsterdam, 21-25 September 1970 (Inst. Met., London, 1970), pp. 106-110.

${ }^{39}$ K. G. Foote, H. P. Knudsen, G. Vestnes, R. Brede, and R. L. Nielsen, "Improved calibration of hydroacoustic equipment with copper spheres," Coun. Meet. Int. Coun. Explor. Sea 1981/B:20, Copenhagen, Denmark, 18 pp. 